\title{
The "Health Coaching" programme: a new patient-centred and visually supported approach for health behaviour change in primary care
}

\author{
Stefan Neuner-Jehle ${ }^{1,3^{*}}$, Margareta Schmid ${ }^{2}$ and Ueli Grüninger 2,3
}

\begin{abstract}
Background: Health related behaviour is an important determinant of chronic disease, with a high impact on public health. Motivating and assisting people to change their unfavourable health behaviour is thus a major challenge for health professionals. The objective of the study was to develop a structured programme of counselling in primary care practice, and to test its feasibility and acceptance among general practitioners (GPs) and their patients.

Methods: Our new concept integrates change of roles, shared responsibility, patient-centredness, and modern communication techniques - such as motivational interviewing. A new colour-coded visual communication tool is used for the purpose of leading through the 4-step counselling process. As doctors' communication skills are crucial, communication training is a mandatory part of the programme. We tested the feasibility and acceptance of the "Health Coaching" programme with 20 GPs and 1045 patients, using questionnaires and semistructured interviewing techniques. The main outcomes were participation rates; the duration of counselling; patients' self-rated behavioural change in their areas of choice; and ratings of motivational, conceptual, acceptance, and feasibility issues.
\end{abstract}

Results: In total, 37\% ( $n=350)$ of the patients enrolled in step 1 completed the entire 4-Step counselling process, with each step taking 8-22 minutes. 50\% of ratings ( $n=303$ ) improved by one or two categories in the three-colour circle, and the proportion of favourable health behaviour ratings increased from $9 \%$ to $39 \%$. The ratings for motivation, concept, acceptance, and feasibility of the "Health Coaching" programme were consistently high.

Conclusions: Our innovative, patient-centred counselling programme for health behaviour change was well accepted and feasible among patients and physicians in a primary care setting. Randomised controlled studies will have to establish cost-effectiveness and promote dissemination.

Keywords: Health behaviour, Short intervention, Motivational interviewing, Family medicine, Primary care, Counselling, Patient-centredness, Health promotion

\section{Background}

In addition to non-modifiable factors-such as genetic disposition, sex, age, and ethnicity-health related behaviour is an important determinant of chronic disease (for example, coronary heart disease, cardiovascular disease (CVD), and stroke), with a high impact on the evolution and course of the disease [1]. CVD is a major

\footnotetext{
* Correspondence: sneuner@bluewin.ch

'Institute of General Practice and Health Services Research, University of Zürich, Pestalozzistrasse 24, Zürich 8091, Switzerland

${ }^{3}$ Swiss College of Primary Care Medicine, Bern, Switzerland

Full list of author information is available at the end of the article
}

issue in public health, contributing excessively to the overall morbidity and mortality in the populations of industrialised societies [2]. This highlights an urgent need for action to diminish the burden of disease. Other important diseases-such as malignancy, dementia, and diabetes-are also associated at least partially, owing to behaviourally modifiable risk factors. The most relevant areas of health related behaviour are therefore dietary habits and body weight control, physical activity, smoking, alcohol consumption, and psychosocial stress [1].

\section{Biomed Central}

(c) 2013 Neuner-Jehle et al.; licensee BioMed Central Ltd. This is an Open Access article distributed under the terms of the Creative Commons Attribution License (http://creativecommons.org/licenses/by/2.0), which permits unrestricted use, distribution, and reproduction in any medium, provided the original work is properly cited. 
Motivating and assisting people to change their unfavourable health behaviour is a major challenge for health professionals. Growing evidence suggests that involving people in decision-making is fostering their sense of self-determination, self-responsibility, and ownership, and has positive effects in terms of their motivation, satisfaction, adherence to an intervention, and even health outcomes [3,4]. Patients increasingly seek more active participation in healthcare decisions, albeit not all of them to the same degree [5]. Experts have called for a shift towards a meaningful dialogue between patients and physicians and shared decision making [6].

In the well-known transtheoretical model of behaviour change proposed by Prochaska and DiClemente [7], a change of behaviour requires awareness and knowledge of the relevant problem as necessary prerequisites. Informing persons at risk in the optimal way, in order to create motivation, is not easy and requires attention. In addition to using words and numbers to explain risk, visual communication tools seem to improve the understanding of risk and to increase self-efficacy while dealing with risk $[8,9]$.

\section{Concept}

\section{Concept of the "Health Coaching" project}

Since 2006, a task force of the Swiss College of Primary Care Medicine developed a programme for behavioural counselling and health promotion in primary care. The innovative components of this programme are as follows:

\section{-A change of roles and sharing responsibility between} doctor and patient: Patient and general practitioner (GP) are a team. As a coach, the GP transfers the responsibility for health partly to the patient, who becomes the main actor for her/his health. Patients will be planning and implementing their own health projects step by step, based on their own preferences and experiences. If necessary, other professionals and services can be included, for example, practice staff or third party counsellors.

\section{-Patient-centred choice of the area of action:} Programmes have traditionally focused on one topic-for example, weight control, alcohol consumption, or smoking cessation. The "Health Coaching" programme offers a choice of six topics that are crucial for health, either at an individual level or from a public health perspective (these are the six most important behavioural contributors to the burden of disease in Switzerland): dietary habits and body weight control, physical activity, smoking, alcohol consumption, and psychosocial stress [1]. Out of these six, the patient - who is at the centre - can choose according to her/his preferences and subjectively perceived needs. Additionally, patients may choose other topics-for example, sleep deprivation-as other, potentially harmful, health-related behaviours.

-The counselling techniques are based on modern communication concepts specifically operationalised for use in office consultations: health literacy and patient empowerment [10], shared decision making [11], transtheoretical model of behaviour change (TTM) [7], counselling based on motivational stages [12], motivational interviewing [13], and various risk communication formats and models [14].

-GP training courses (communication skills, especially motivational interviewing techniques) are mandatory, as the change of role and communication techniques are beyond the traditional patterns of GPs' training and professional work. Analogous to the stepwise counselling with patients (see below), the training courses are organised stepwise: a. sensitisation workshops ( $2-3 \mathrm{hrs})$, b. skills training courses $(2 \times 1$ day, with standardised patients), and c. feedback sessions to share experiences.

\section{The concept of the pictorial tool}

The risk visualisation tool (Figure 1) is the central communication element of the programme. It includes categorisation by colour coding to suggest safety or danger to patients at baseline. It facilitates a choice of the six potential areas of action, as a comparison with other areas is possible at one glance. During counselling, repeated use of the tool visualises for the patient the change of behaviour over time: "Am I successful in changing my behaviour (moving from an unfavourable

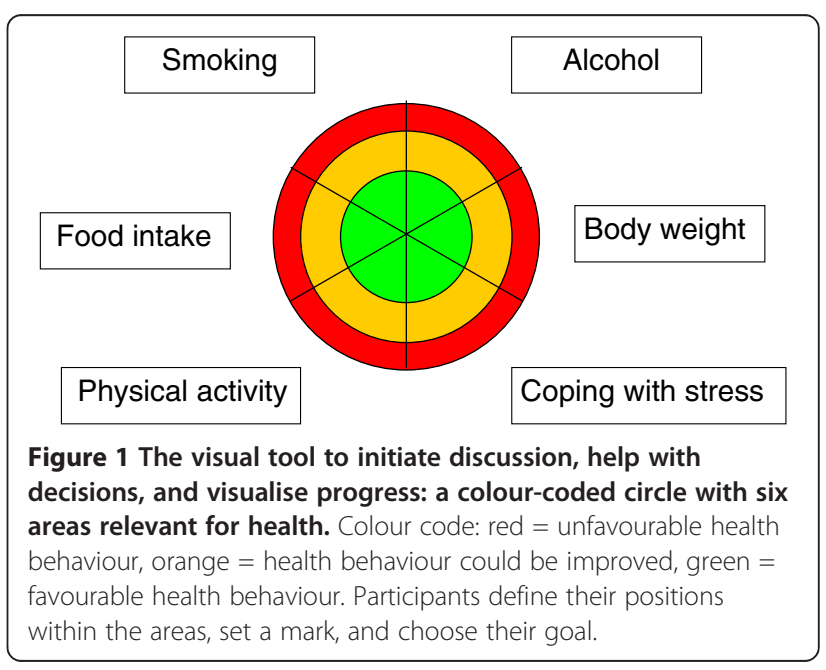


outer zone in the circle to a more favourable, more central zone in the circle), or not yet?" The current category of risk at baseline and its development during the "personal project" are discussed by GPs and patients by using a combination of verbal and visual communication formats. According to the recent literature, such a combination of different communication formats is necessary for optimal understanding $[15,16]$.

\section{Counselling step by step}

Each step of counselling in the Health Coaching programme refers to a step of change in awareness, motivation, or action on the part of patient, in the sense of the TTM [7] stages of behavioural change (Figure 2). This process is based on the fact that on beginning counselling, people are at various stages of change or readiness for a change:

- Step 1 - sensitize: GPs introduce a change of roles and responsibilities. For example, GPs may switch from the paternal role to the coaching role, asking: "Until now, we have been talking about what I can do to help with your illness. Now, I'm interested to know what you want to do for your own health-is that okay with you?" If patients agree, they will assess their own health behaviour and motivation to change.

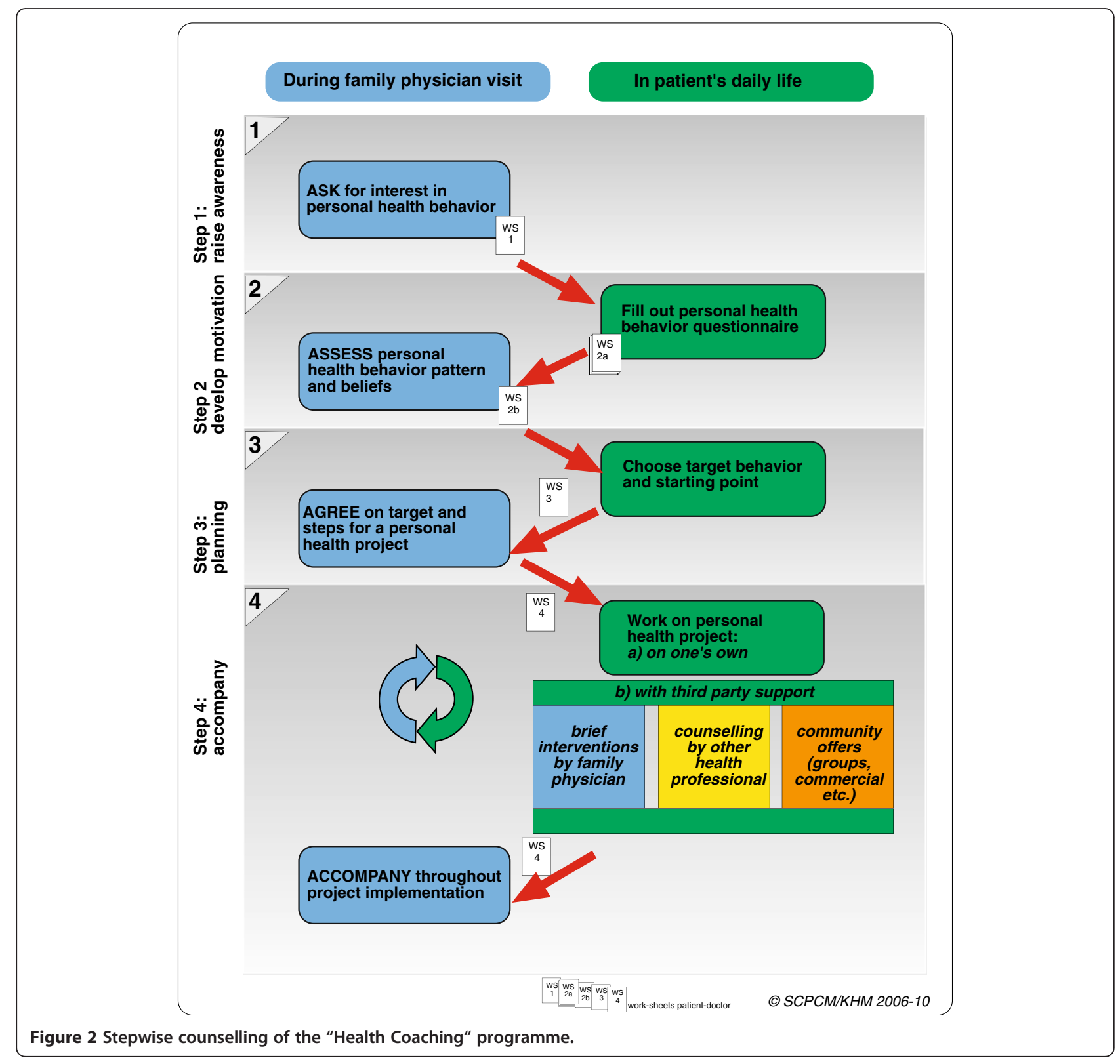


In this initial session the decisive change of focus and distribution of role and responsibility are best introduced by the patient's physician. Later, the counselling may be supported and/or continued by other qualified medical personnel such as trained practice staff.

- Step 2 - create and promote motivation: Health behaviour is analysed by using a questionnaire, to quantify behavioural risks in the areas of choice, and combined with a comment of the GP about the findings.

- Step 3 - plan: On the basis of these objective findings, patients choose their topic, define a specific goal, and develop steps for how to get there (thereby designing their personal health project). GPs frame the need for change in a positive way: as an opportunity for improvement rather than for avoiding risks.

- Step 4-action and coaching: Patients implement the plan, dealing with barriers and resources. In follow-up consultations, patients and GPs evaluate progress in the patient's health programme, adapt the programme, and make changes as needed.

\section{Methods}

\section{Feasibility and acceptance study}

In 2009-10, we conducted a feasibility and acceptance study with an extended evaluation to prove these concepts in a canton (Swiss state/district) in eastern Switzerland. After approval by the ethical committee of the Canton St Gallen, we enrolled 20 GPs (by postal invitation), who in turn recruited 1045 patients into the study during a 12-month period. Written, informed consent for participation in the study was obtained from participants. The mean age of patients was 50 (range 15-75) years, 53\% were men. Participants' health behaviours in the six areas and educational attainments were close to those of the average population in Switzerland. Figure 3 shows the workflow of counselling, rates of patient participation from one step to the next, and the times of data collection. We collected data from the patient-doctor worksheets used in the office consultations, patient questionnaires after counselling, office log books documenting the duration of counselling sessions, participants' questionnaires at different times in the process, GPs' questionnaires, semistructured interviews with GPs at the end of the 12 month study period, and GPs' group interviews during the training courses and feedback meetings. We used SPSS (Statistical Software Package, Version 19, SPSS Inc., Chicago, Illinois) for our statistical analysis, and we calculated means, medians, standard deviations (SDs), and interquartile ranges (IQRs). The qualitative data were categorised based on thematic content analysis.

\section{Results}

Participation rates were 91\% for Step 1 and 65\%, 70\%, and $81 \%$ for Steps two, three, and four, respectively. In total, $37 \%(n=350)$ of the patients enrolled in Step 1 completed the 4-step counselling process. On average, every GP undertook counselling with 45 patients within this 12 month period, with a mean duration of $7.7 \mathrm{mi}-$ nutes for Step 1 (SD 4.2, median 6, IQR 5-10), 21.9 minutes for Step 2 (SD 9.5, median 20, IQR 15-30), 20.3

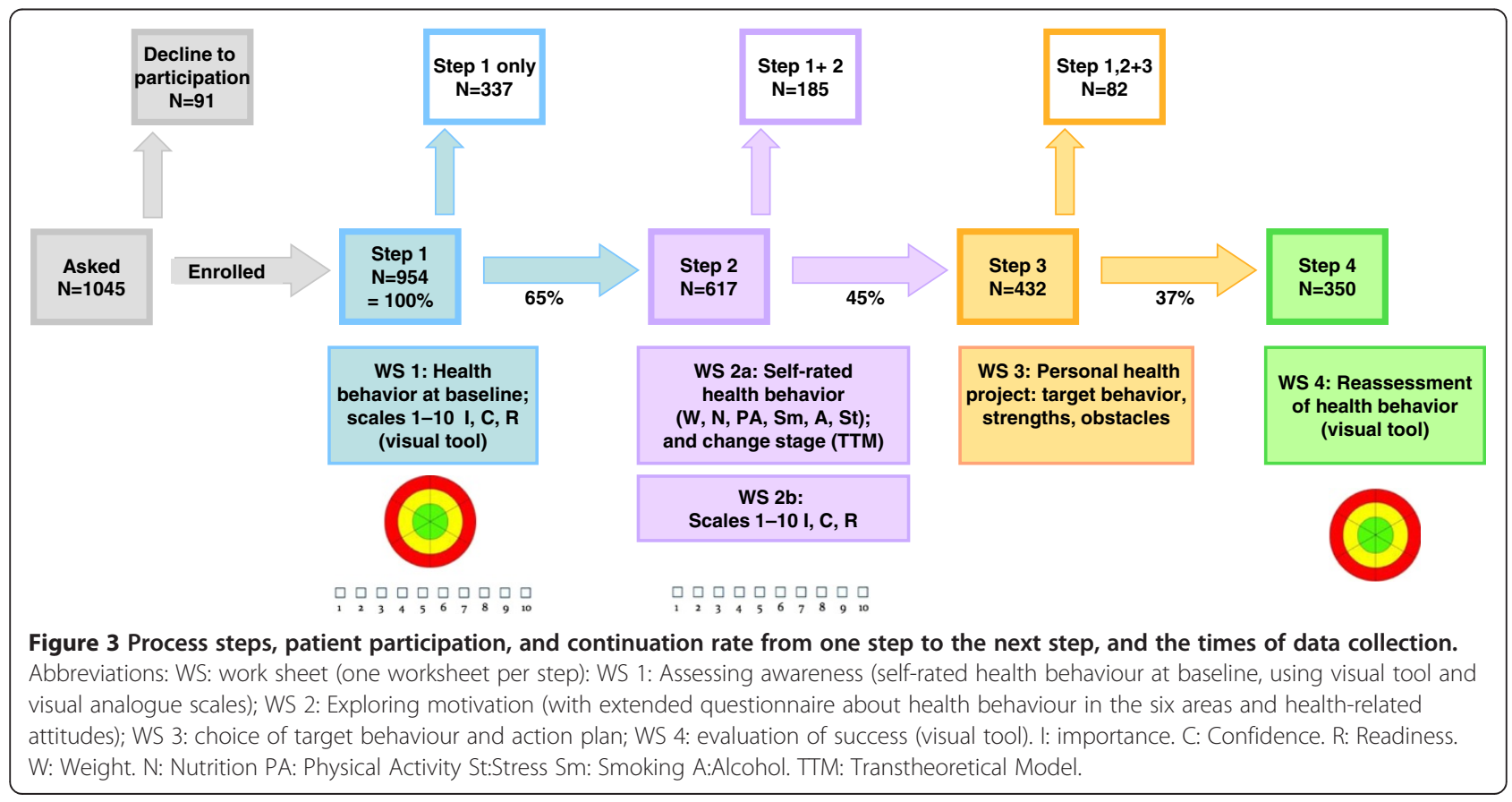


minutes for Step 3 (SD 8.8, median 20, IQR 15-25), and 18.2 minutes for Step 4 (SD 8.8, median 16, IQR 12-20).

The self-rated importance, self-confidence (to reach the goal), and readiness to change were 8.3 (SD 1.8), 7.3 (SD 2.1), and 7.8 (SD 2.1) points on a 10-point Likert scale at the beginning, and increased throughout the counselling. One third of 528 targets chosen by participants at Step 3 related to weight control and 20\% to physical activity. Eating habits, tobacco smoking and coping with stress accounted for 12 to $13 \%$ each, alcohol consumption for $2 \%$, and other goals (symptom control, wellbeing, or better health generally) for $8 \%$. Acceptance and feasibility rating by patients were generally high (between 3.3 and 3.8 points on a 4-point Likert scale, SD 0.44-0.77) for concept, materials, the role of the GP, and overall usefulness (Table 1). Quantitative and qualitative data from GPs show similarly positive feedback: the new, more relaxed approach to the patient improved work quality and satisfaction. GPs felt relieved to hand over responsibility and share it with the patients. The "Health Coaching" programme seems to empower GPs to address health related issues during patient encounters. After the end of the 12 month study period, 16 of the 20 study GPs spontaneously expressed that they wanted to continue with the programme.

The pictorial tool was rated 3.5 (SD 0.65) in terms of being helpful and practicable, and higher in Steps 3 and 4 of counselling (3.6, SD 0.55). Similarly, GPs gave positive feedback regarding the tool, considering it to be a helpful schematic and vehicle for counselling in terms of conveying information, stimulating awareness, and visualising comparisons across behaviours and changes of these.

Some $46 \%$ of participants' health behaviour ratings $(n=403)$ in their targeted area of choice at Step 1 defined in the unfavourable category (red area), compared with $21 \%$ after counselling $(\mathrm{n}=303)$, and $9 \%$ defined in the favourable category (green area), compared with 39\% after counselling (Figure 4). Among participants who completed the counselling programme, $50 \%$ of ratings $(n=303)$ improved by one or two categories in the threecolour circle, $43 \%$ of ratings did not change category, and $7 \%$ deteriorated by one category. The proportions differed to a small degree, depending on the targeted area chosen (Table 2). Among participants without subjective behavioural improvement, most experienced a subjective benefit from counselling, regardless, as measured by indices of attributed importance, selfconfidence, and stage of readiness: - "I have learned that this is not about my blood pressure, but about me as a person, and that it is me who is responsible for my health, and that I can't delegate this to my physician". "Being more active can be fun." - "I often remember what I discussed with my GP". Participants increased their knowledge and awareness of their health behaviours and learned to seek support, if necessary.

\section{Discussion}

To our knowledge, the "Health Coaching" project is the first multidimensional, patient-centred and systematic approach to foster GPs' counselling about health relevant behaviour. The high participation rate at baseline and

Table 1 Items and ratings of participants in regard to acceptance and feasibility; rating on a 4-point-Likert scale: Category 1 =strongly disagree, 2=somewhat disagree, 3=somewhat agree, 4=strongly agree

\begin{tabular}{|c|c|c|c|c|c|c|}
\hline Item in the questionnaire & mean & SD & Cat. 1 & Cat. 2 & Cat. 3 & Cat. 4 \\
\hline I appreciate that my GP asked me to join the program. & 3.7 & 0.56 & $1 \%$ & $2 \%$ & $20 \%$ & $76.4 \%$ \\
\hline I appreciate my GP's support in improving my health. & 3.8 & 0.44 & $0.3 \%$ & $1.1 \%$ & $16.9 \%$ & $81.7 \%$ \\
\hline It is important that I myself can do something to improve my health. & 3.8 & 0.48 & $0 \%$ & $1.8 \%$ & $21.8 \%$ & $76.4 \%$ \\
\hline The procedure using work sheets is useful and meets my current needs. & 3.4 & 0.62 & $0.4 \%$ & $5.7 \%$ & $43.3 \%$ & $50.6 \%$ \\
\hline $\begin{array}{l}\text { The three-coloured circle was useful in defining for myself my own position regarding } \\
\text { the different health behaviours. }\end{array}$ & 3.5 & 0.65 & $1.4 \%$ & $4.8 \%$ & $39.4 \%$ & $54.4 \%$ \\
\hline The questionnaire helped me see where I could improve my health behaviour. & 3.5 & 0.64 & $1 \%$ & $5 \%$ & $36.6 \%$ & $57.4 \%$ \\
\hline My doctor's regular feedback improved my motivation to stick to my goals. & 3.4 & 0.71 & $1.9 \%$ & $7.6 \%$ & $39.7 \%$ & $50.8 \%$ \\
\hline My doctor took enough time to talk to me about the work sheets. & 3.7 & 0.64 & $1.8 \%$ & $3.7 \%$ & $21.7 \%$ & $72.8 \%$ \\
\hline My doctor was always concerned about my needs during the discussions. & 3.7 & 0.47 & $0 \%$ & $1.1 \%$ & $25.3 \%$ & $73.6 \%$ \\
\hline I was able to discuss my most important health issues with my doctor. & 3.8 & 0.48 & $0 \%$ & $2.3 \%$ & $18.9 \%$ & $78.8 \%$ \\
\hline $\begin{array}{l}\text { Since then, I have become more confident that I am able to change my own health } \\
\text { behaviour (to have an influence on my health, respectively). }\end{array}$ & 3.3 & 0.69 & $1 \%$ & $9.5 \%$ & $47.6 \%$ & $41.9 \%$ \\
\hline My doctor's support has increased my self confidence that I am able to achieve a change. & 3.5 & 0.63 & $0 \%$ & $7.4 \%$ & $36.8 \%$ & $55.8 \%$ \\
\hline For me, participating in the "Health Coaching" programme has been worth while. & 3.4 & 0.77 & $2.3 \%$ & $10.6 \%$ & $29.9 \%$ & $57.1 \%$ \\
\hline $\begin{array}{l}\text { I think the "Health Coaching" programme should be part of a GP's standard } \\
\text { practice offerings. }\end{array}$ & 3.6 & 0.66 & $1.1 \%$ & $5.9 \%$ & $30.6 \%$ & $62.5 \%$ \\
\hline
\end{tabular}




\section{Before counselling}

All areas of choice $n=403$

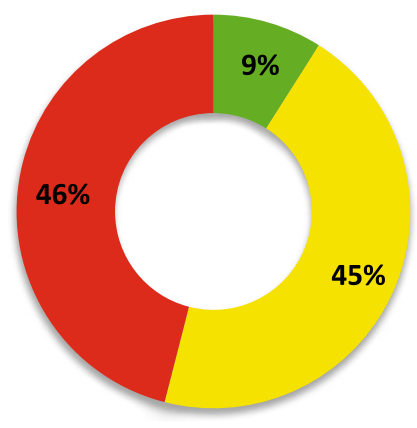

\section{After counselling}

All areas of choice $n=303$

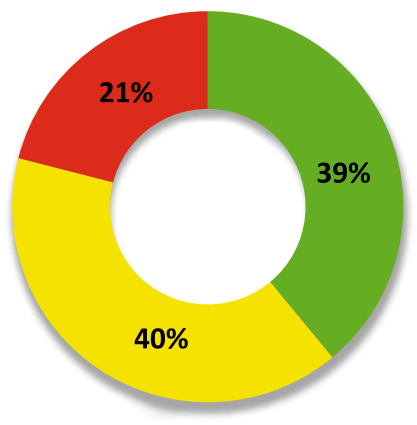

\footnotetext{
wealth behaviour favourable

health behaviour could still be improved

health behaviour unfavourable
}

Figure 4 Proportion of participants in the three possible categories of health behaviour, in their area of choice, before and after counselling (self-ratings). Numbers before and after counselling are not consistent because of discontinuation of the stepwise counselling procedure and missed items. Numbers refer to targets (areas of choice), not to participants.

the above-average adherence rates throughout the 4-step counselling process are strong indicators of acceptance and feasibility of our approach, as are the high ratings related to these topics from the patients' and GPs' questionnaires and interviews. For GPs, 1-2 starting sessions and 2-3 complementary (Step 2-4) sessions per week should present an acceptable supplementary workload in their practices, and the counselling times (8 to $22 \mathrm{mi}-$ nutes) still meet the criteria of a short intervention and cost-effectiveness.

We were encouraged by the patients' high self-ratings of motivation and readiness to change at baseline. The Health Coaching programme appears to have met patients' needs, traditionally unmet and undervalued, with respect to discussing health promotion topics with their
GPs. The fact that the ratings of importance, selfconfidence (to reach the goal), and readiness to change increased during counselling underlines the efficacy of our approach, although selection bias might limit the validity of these findings (see below).

The use of colours in our pictorial tool provided patients with an important reference point regarding the severity of risk. In this colour coding, the colour red denotes urgency (even danger) and the necessity to discontinue the behaviour, whereas the green colour denotes "no risk" [17]. This coding system relies on what most of us learn early in our childhood: the symbolism of traffic light colours. In the meantime, many risk calculators are using colour-coded tables or output categories [18]; consequently, this method of communication has become

Table 2 Change in self-defined categories of health behaviour, in the six areas of choice, after completing the four-step counselling procedure

\begin{tabular}{lccc}
\hline Target (area of choice) & Improvement by 1-2 categories & No change of categories & Deterioration by 1-2 categories \\
\hline Body weight $n=106$ & $43 \%$ & $53 \%$ & $4 \%$ \\
Physical activity $n=75$ & $52 \%$ & $35 \%$ & $13 \%$ \\
Eating pattern $n=42$ & $49 \%$ & $46 \%$ & $5 \%$ \\
Coping with stress $n=38$ & $58 \%$ & $34 \%$ & $8 \%$ \\
Smoking $n=35$ & $60 \%$ & $37 \%$ & $3 \%$ \\
Alcohol consumption $n=7$ & $57 \%$ & $43 \%$ & $0 \%$ \\
Total $\mathbf{n}=\mathbf{3 0 3}$ & $\mathbf{5 0 \%}$ & $\mathbf{4 3 \%}$ & $\mathbf{7 \%}$ \\
\hline
\end{tabular}

*Numbers of targets (areas of choice) relate to data from 231 participants who completed Step 4, which is equivalent to 303 targets (several participants defined more than one target for their personal project). Of all participants completing Step $4(n=350)$, data on these Step 4 target ratings were missing in 119 participants, as the visual tool in Step 4 was designed as counselling support and not primarily as data collection tool. 
familiar. Patients seem to feel a need to compare themselves to an average value (or population) [19], and the result may improve their motivation to change, or, equally important, when they report being in the healthy (green) range, this can help them to sustain existing or recently acquired beneficial habits.

The main finding is an improvement in self-rated health behaviour by at least one of two possible levels in half of the participants in the Health Coaching programme; those showing no behavioural improvement reported some benefit as well. This benefit translates into an increase in awareness, perceived self-confidence, and readiness to take responsibility. In comparison to other preventive interventions, the "number needed to treat" (NNT) in our intervention to achieve a successful change of health behaviour, is low. In order to change behaviour successfully in one patient, we had to invite six patients to participate (one in three participants completed the four counselling steps, and one in two completers changed their behaviour successfully). The positive effects observed in the participants who did not complete the programme or in participants who did not report improvement are additional positive outcomes; this further improves the effort to benefit ratio.

Although acceptance and feasibility were high, research is needed to elucidate barriers among patients and GPs against the use of programmes similar to our's, and to identify factors that may promote and facilitate this sort of approach. We suggest exploratory studies with focus groups, and interviewing techniques focusing on these factors. More studies with a randomised controlled design and a longer follow-up period are needed to establish objective and clinically relevant outcomes. Finally, the cost effectiveness of the Health Coaching programme will have to be investigated, by means of health services research, for example, on how biomedical or surgical interventions can be avoided by successful health behaviour changes in response to counselling.

In sum, our programme is innovative and atientcentred. It appeared to be well accepted by patients and GPs, and highly feasible in a primary care setting. To publicise this approach and programme among GPs, several issues need to be addressed. These include the smooth integration into busy office schedules and doctors' workload, as well as the introduction of appropriate reimbursement for the counselling sessions. Sharing counselling activities with other health professionals, e.g. practice staff, may be one way to facilitate this. The extension of health behaviour change competencies is necessary at various levels: in the education of physicians (undergraduate and postgraduate training, as well as in continuous medical education); in practice-based research; in medical associations, in order to recognise these skills as basic medical competencies; and in the support of health policymakers at the legislative, executive, and regulatory levels. Finally, extending our Health Coaching programme to other healthcare professionals, including non academic professionals, is a promising option in order to promote its effects. Feasibility studies to explore this topic and access to it are necessary [20].

\section{Limitations}

Our feasibility and acceptability study was run in one region of Switzerland, with a relatively small number of GPs; therefore, the results have limited generalisability. Most outcomes were self-reports rather than clinical outcomes, as we did not have the intention nor the means to conduct a randomised controlled trial to measure the clinical effects of the intervention, but, rather, to test our approach and its acceptance and feasibility.

We cannot exclude selection bias owing to the way in which GPs and patients were recruited: GPs with a higher motivation for counselling activities in health behaviour may have been more inclined to accept the invitation, and patients willing to participate may have been more motivated to start counselling and undertake activities to change their behaviour than those who declined. The unexpectedly high rates of motivation (preparation stage of the TTM model) for a change at baseline may be an indicator of a possible bias. However, the fact that only $9 \%$ of invited patients declined participation minimises this possible bias, and the proportion of invited patients who highly appreciated a discussion about their health behaviour with their GPs (three out of four) was not significantly different from an average European general practice population [21]. Without a randomised controlled study, it is difficult to estimate the size of this selection bias, and the main focus of our study was the feasibility and acceptance.

In regard to the pictorial risk communication tool, it was not our intention to validate the tool independently of the counselling effect. A full validation would require a randomised controlled design and a separation of communication tool and counselling as interventions. Regardless, we included patient ratings and GPs' comments about the pictorial tool in the evaluation.

\section{Conclusions}

To our knowledge, our "Health Coaching" programme is the first multidimensional, patient-centred and systematic programme that has been designed to promote GPs' counselling about health-related behaviour, and has been shown to be feasible and acceptable to patients in a primary care setting.

Further studies are needed including randomised controlled trials to examine the cost effectiveness of health coaching by GPs, with measurable and clinically relevant outcomes. The results will hopefully encourage stakeholders 
and politicians to take responsibility for supporting health promoting programmes in primary care. This may facilitate dissemination, in order to improve health related behaviours at an individual and public health level, thereby helping to reduce the burden of non-communicable diseases. In the face of these diseases, such programmes may be singularly important in reversing this epidemic.

\section{Abbreviations}

CVD: Cardiovascular disease; GP: General practitioner; IQR: Interquartile range; NNT: Number needed to treat; RCT: Randomised controlled trial; SD: Standard deviation; TTM: Transtheoretical model of behaviour change.

\section{Competing interests}

The authors declared that they have no conflict of interest.

\section{Authors' contributions}

UG, SNJ, and MS developed the concept and designed the feasibility and acceptance study. MS conceived the evaluation process, carried out the data collection, and performed the statistical analysis. SNJ drafted the manuscript. All authors contributed to the writing of the manuscript, and all authors read and approved the final manuscript.

\section{Acknowledgements}

We thank the study GPs, their practice teams, and the patients for participation. We thank the Society of Physicians of the Canton St Gallen and the Health Department of the Canton St Gallen for supporting the implementation of the project. We thank our project managers Ruedi Hösli, Murielle Mérinat, and Fabian Egli for their enthusiastic contributions. The study was supported by the following organisations (none had any influence on the content): Health Promotion Switzerland; Federal Tobacco Prevention Fund; Pfizer AG; Swiss Cancer League; Swiss Federal Office of Public Health; Swiss Conference of Cantonal Ministers of Public Health; Fondation Sana; Novartis Pharma Schweiz AG.; MSD Merck Sharp \& Dohme AG; Swiss Association for Smoking Prevention; Sanofi-Aventis Schweiz AG; Swiss Heart Foundation.

\section{Author details}

${ }^{1}$ Institute of General Practice and Health Services Research, University of Zürich, Pestalozzistrasse 24, Zürich 8091, Switzerland. ${ }^{2}$ Institute of Social and Preventive Medicine, University of Zürich, Zürich 8091, Switzerland. ${ }^{3}$ Swiss College of Primary Care Medicine, Bern, Switzerland.

Received: 1 February 2013 Accepted: 15 July 2013

Published: 17 July 2013

\section{References}

1. Yusuf S, Hawken S, Öunpuu S, Dans T, Avezum A, Lanas F, McQueen M, Budaj A, Pais P, Varigos J, Lisheng L: Effect of potentially modifiable risk factors associated with myocardial infarction in 52 countries (the INTERHEART study): case-control study. Lancet 2004, 364:937-952.

2. Roger VL, Go AS, Lloyd-Jones DM, Benjamin EJ, Berry JD, Borden WB, Bravata DM, Dai S, Ford ES, Fox CS, Fullerton HJ, Gillespie C, Hailpern SM, Heit JA, Howard VJ, Kissela BM, Kittner SJ, Lackland DT, Lichtman JH, Lisabeth LD, Makuc DM, Marcus GM, Marelli A, Matchar DB, Moy CS, Mozaffarian D, Mussolino ME, Nichol G, Paynter NP, Soliman EZ, Sorlie PD, Sotoodehnia N, Turan TN, Virani SS, Wong ND, Woo D, Turner MB, American Heart Association Statistics Committee and Stroke Statistics Subcommittee: Heart disease and stroke statistics-2012 update: a report from the American Heart Association. Circulation 2012, 125:2-220.

3. Van Steenkiste $B$, van der Weijden T, Stoffers HE, Kester AD, Timmermans $\mathrm{DR}$, Grol R: Improving cardiovascular risk management: a randomized controlled trial on the effect of a decision support tool for patients and physicians. Eur J Cardiovasc Prev Rehabil 2007, 14:44-50.

4. O'Connor AM, Stacey D, Entwistle V, Llewellyn-Thomas H, Rovner D, Holmes-Rovner M, Tait V, Tetroe J, Fiset V, Barry M, Jones J: Decision aids for people facing health treatment or screening decisions. Cochrane Database Syst Rev 2009, CD001431.
5. Levinson W, Kao A, Kuby A, Thisted R: Not all patients want to participate in decision making. A National Study of Public Preferences. J Gen Intern Med 2005, 20:531-535.

6. Politi MC, Han PKJ, Col NF: Communicating the uncertainty of harms and benefits of medical interventions. Med Decis Making 2007, 27:681-695.

7. Prochaska JO, DiClemente CC: Towards a comprehensive model of change: Treating addictive behaviors. In Processes of change. Edited by Miller WR, Heather N. New York: Plenum Press; 1986.

8. Waldron CA, van der Weijden T, Ludt S, Gallacher J, Elwyn G: What are effective strategies to communicate cardiovascular risk information to patients? A systematic review. Pat Educ Couns 2011, 82:169-181.

9. Price M, Cameron R, Butow P: Communicating risk information: The influence of graphical display format on quantitative information perception - accuracy, comprehension and preferences. Pat Educ Couns 2007, 69:121-128.

10. Feste C, Anderson R: Empowerment: from philosophy to practice. Pat Educ Couns 1995, 26:139-144.

11. Makoul G, Clayman M: An integrative model of shared decision making in medical encounters. Pat Educ Couns 2006, 60:301-312.

12. Grüninger U, Duffy FD, Goldstein MG: Patient Education in the Medical Encounter: How to Facilitate Learning, Behavior Change, and Coping. In The Medical Interview: Clinical Care, Education, and Research. Edited by Lipkin M, Putnam SM, Lazare A. New York: Springer-Verlag; 1995.

13. Miller WR, Rollnick S: Motivational Interviewing. Preparing People for Change. New York, London: The Guilford Press; 2002.

14. Alaszewski A, Horlick-Jones T: How can doctors communicate information about risk more effectively? Br Med J 2003, 327:728-731.

15. Goodyear-Smith F, Kenealy T, Wells S, Arroll B, Horsburgh M: Patients preferences for ways to communicate benefits of cardiovascular medication. Ann Fam Med 2011, 9:121-127.

16. Neuner-Jehle S, Senn O, Wegwarth O, Rosemann T, Steurer J: How do family physicians communicate about cardiovascular risk? Frequencies and determinants of different communication formats. BMC Fam Pract 2011, 12:15

17. Hill S, Spink J, Cadilhac D, Edwards A, Kaufman C, Rogers S, Ryan R, Tonkin A: Absolute risk representation in cardiovascular disease prevention: comprehension and preferences of health consumers and general practitioners involved in a focus group study. BMC Publ Health 2010, 10:108.

18. Conroy RM, Pyörälä K, Fitzgerald AP, Sans S, Menotti A, De Backer G, De Bacquer D, Ducimetière $P$, Jousilahti $P$, Keil U, Njølstad I, Oganov RG, Thomsen $T$, Tunstall-Pedoe $H$, Tverdal A, Wedel H, Whincup P, Wilhelmsen L, Graham IM, SCORE project group: Estimation of ten-year risk of fatal cardiovascular disease in Europe: the SCORE project. Eur Heart J 2003, 24:987-1003. http://www.heartscore.org

19. Fagerlin A, Zikmund-Fisher BJ, Ubel PA: "If I'm better than average, then I'm ok?": Comparative information influences beliefs about risk and benefits. Pat Educ Couns 2007, 69:140-144.

20. Geense W, van de Glind I, Visscher T, van Achterberg T: Barriers, facilitators and attitudes influencing health promotion activities in general practice: an explorative pilot study. BMC Fam Pract 2013, 14:20.

21. Brotons C, Bulc M, Sammut MR, Sheehan M, ManueldaSilva Martins C, Björkelund C, Drenthen AJ, Duhot D, Görpelioglui S, Jurgova E, Keinanen-Kiukkanniemi S, Kotányi P, Markou V, Moral I, Mortsiefer A, Pas L, Pichler I, Sghedoni D, Tataradze R, Thireos E, Valius L, Vuchak J, Collins C, Cornelis E, Ciurana R, Kloppe P, Mierzecki A, Nadaraia K, Godycki-Cwirko M: Attitudes toward preventive services and lifestyle: the views of primary care patients in Europe. The EUROPREVIEW patient study. BMC Fam Pract 2012, 1:168-176.

doi:10.1186/1471-2296-14-100

Cite this article as: Neuner-Jehle et al:: The "Health Coaching" programme: a new patient-centred and visually supported approach for health behaviour change in primary care. BMC Family Practice $201314: 100$ 